\title{
Article \\ Substrate-Integrated Waveguide Microwave Sensor for Water-in-Diesel Fuel Applications
}

\author{
Antonella Maria Loconsole (D), Vito Vincenzo Francione, Vincenza Portosi (D), Onofrio Losito, Michele Catalano, \\ Attilio Di Nisio (D), Filippo Attivissimo (D) and Francesco Prudenzano * (D)
}

Department of Electrical and Information Engineering, Politecnico di Bari, Via Orabona, 4, 70125 Bari, Italy; antonellamaria.loconsole@poliba.it (A.M.L.); v.francione@studenti.poliba.it (V.V.F.); vincenza.portosi@poliba.it (V.P.); onofrio.losito@poliba.it (O.L.); m.catalano6@studenti.poliba.it (M.C.); attilio.dinisio@poliba.it (A.D.N.); filippo.attivissimo@poliba.it (F.A.)

* Correspondence: francesco.prudenzano@poliba.it

check for updates

Citation: Loconsole, A.M.; Francione, V.V.; Portosi, V.; Losito, O.; Catalano, M.; Di Nisio, A.; Attivissimo, F.; Prudenzano, F. Substrate-Integrated Waveguide Microwave Sensor for Water-in-Diesel Fuel Applications. Appl. Sci. 2021, 11, 10454. https:// doi.org/10.3390/app112110454

Academic Editors: Adel Razek and Ernesto Limiti

Received: 10 August 2021

Accepted: 3 November 2021

Published: 7 November 2021

Publisher's Note: MDPI stays neutral with regard to jurisdictional claims in published maps and institutional affiliations.

Copyright: (c) 2021 by the authors. Licensee MDPI, Basel, Switzerland. This article is an open access article distributed under the terms and conditions of the Creative Commons Attribution (CC BY) license (https:/ / creativecommons.org/licenses/by/ $4.0 /)$.

\begin{abstract}
A water-in-diesel microwave sensor based on a substrate integrated waveguide (SIW) microwave applicator is designed and characterized in this study. The interaction between the microwave electromagnetic field and the diesel fuel contaminated with small concentrations of water is obtained via suitable radiating slots placed on the top of an SIW waveguiding structure. The SIW applicator working frequency is chosen by observing the behavior of the complex dielectric permittivity of the fuel-water blend based on a preliminary wide band investigation. The performances of the SIW microwave sensor are evaluated in terms of scattering parameter modulus $\left|S_{21}\right|$ as a function of the water concentration in ppm. The best sensitivity $\frac{\Delta\left|S_{21}\right|}{\Delta \rho}=1.42 \mathrm{mdB} / \mathrm{ppm}$ is obtained at a frequency of $f=9.76 \mathrm{GHz}$, with a coefficient of determination $R^{2}=0.94$. The sensor is low-cost, low profile and ensures a good sensitivity for constant and real-time monitoring.
\end{abstract}

Keywords: substrate integrated waveguide (SIW); microwave sensor; water-in-fuel monitoring

\section{Introduction}

The monitoring of hydrocarbon quality is an important goal, not only for modern automotive, industrial and aerospace applications, but also in view of the next uses of biodiesel fuel generation [1,2]. There are many different contaminants that can compromise hydrocarbon quality, such as alcohol, water, ethanol, and oils [3-5]. Monitoring should be fast, accurate and real time, because these contaminants could alter the lubrification properties of fuel and reduce motor performance. In particular, they could alter the viscosity, density, and boiling point of the hydrocarbons [6]. In general, traditional laboratory techniques, such as an evaporation test, distillation, gas chromatography, etc., useful to identify the quality of petroleum liquid and its derivative products, are more expensive and introduce a delay time for analysis. Microwave sensor techniques provide an interesting alternative approach [5-11].

Water in fuel also causes the corrosion of metallic parts [1]. Therefore, conformity and quality standards must be respected for suitable fuel employment. For example, with reference to water in fuel concentrations, EN590 is the European rule defining the standard for automotive and ASTM D1655 for aerospace applications [12-14]. In particular, regarding automotive applications, the water content in fuel must not be over $500 \mathrm{ppm}$ [15]. Water contamination can be detected by using different electromagnetic technologies, including optical fiber gratings and microwave reflection techniques [14-20]. Microwave (MW) sensors can be very efficient devices for real-time water detection, since the dielectric constant of water, $\varepsilon_{r, H 2 O}=70$, is about 40 times the dielectric constant of diesel fuel, $\varepsilon_{r, f u e l}=1.75$, at the frequency $f=10 \mathrm{GHz}$. Many different kinds of devices have been proposed, including coaxial antennas and microstrip sensors, stacked multi ring resonators (SMRR) or vertically stacked ring resonators (VSRR), and microwave resonant cavities [5-11,14,15,20-24]. 
Microstrip technology, in addition to having a number of practical advantages, allows to design compact and integrated devices, but it does not guarantee a complete confinement of the electromagnetic (EM) field and suffers radiating losses. On the other hand, substrate integrated waveguide (SIW) technology allows to obtain compact and low-cost solutions, good performances, integration of active and passive devices on a single substrate, good EM field guidance, a reduction in insertion and radiation losses, and the use of higher power [25-29]. SIW technology is employed in many fields, including aerospace, medical therapy, industrial monitoring, and free-space communications, thanks to the easiness of its construction process [30-39].

In this work, a microwave SIW applicator for water-in-fuel detection is designed and constructed. To the best of our knowledge, the microwave frequency range $f=9-11 \mathrm{GHz}$ is investigated to this aim for the first time, allowing the creation of a very compact device. The sensor characterization, using a vector network analyzer (VNA), confirms the simulation results with a quite good agreement. These performances are intriguing when compared to the literature results $[14,15,22]$.

\section{Water-Fuel Blend Characterization}

The SIW microwave applicator is designed to work in the frequency range $f=9-11 \mathrm{GHz}$ with CST Studio Suite ${ }^{\circledR}$ software. This frequency range was chosen by observing the behavior of the complex dielectric permittivity of the fuel-water blend, on the basis of a wide-band investigation performed with a SPEAG DAK 3.5 probe [40] and a N9927A FieldFox Handheld Microwave Vector Analyzer by Keysight [41]. This preliminary investigation has highlighted changes in complex dielectric permittivity at the aforementioned frequencies, thus promising potential applications for sensing.

Five fuel samples were prepared containing different concentrations of contaminant water. In particular, $\rho=0$ ppm (pure diesel), $\rho=50$ ppm, $\rho=200 \mathrm{ppm}, \rho=500 \mathrm{ppm}$, and $\rho=1000$ ppm of water were prepared. Water concentrations higher than $\rho=500$ ppm were not investigated because they are not interesting for practical applications, as they are over the acceptable limits regarding water contamination. The concentration $\rho=1000 \mathrm{ppm}$ has been taken into account to verify the characteristics slope for extreme contaminations. Figure 1 shows the SPEAG DAK 3.5 probe-N9927A VNA characterization set-up. For each sample, the dielectric constant measurement was repeated seven times. These measurement results have been averaged to reduce measurement noise and fitted with a polynomial. Table 1 reports the order and the coefficient of determination $R^{2}$ of the polynomial fitting the five measured dielectric constant curves. The fitting order has been chosen to maximize $R^{2}$.

The measured complex dielectric constants for the five samples as functions of the frequency are reported in Figure 2 (real part $\varepsilon^{\prime}$ ) and Figure 3 (imaginary part $\varepsilon^{\prime \prime}$ ).

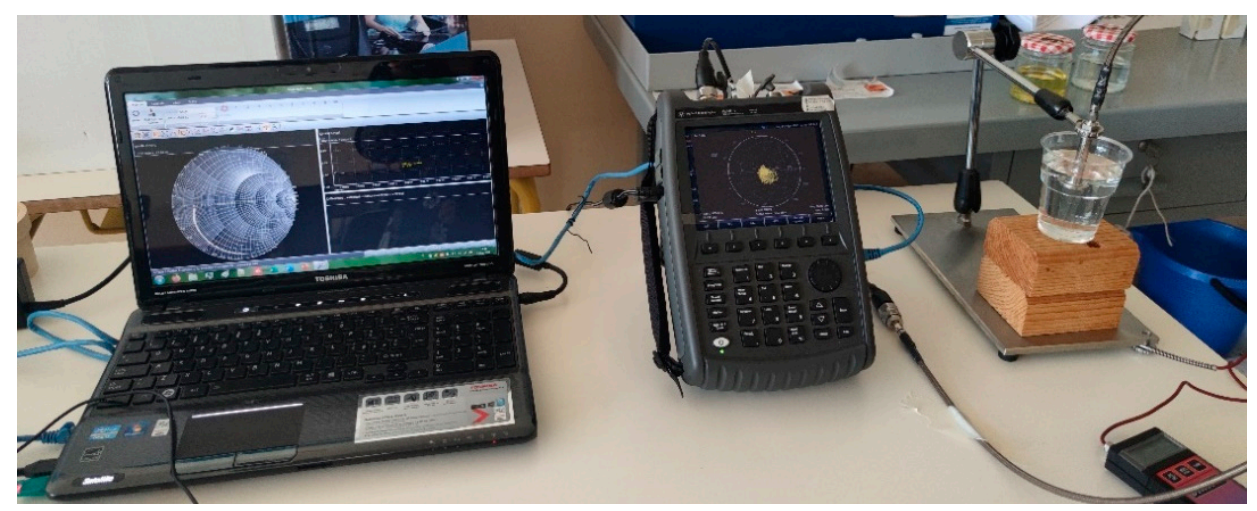

Figure 1. Characterization set-up with VNA Keysight N9927A FieldFox and DAK 3.5 probe. 
Table 1. Order and coefficient of determination $R^{2}$ of the polynomial fitting the measured dielectric constant curves.

\begin{tabular}{ccc}
\hline Sample & Fitting Order & $\boldsymbol{R}^{2}$ of the Polynomial Fitting \\
\hline$\rho=0 \mathrm{ppm}$ & 8 & 0.95 \\
$\rho=50 \mathrm{ppm}$ & 3 & 0.93 \\
$\rho=200 \mathrm{ppm}$ & 3 & 0.97 \\
$\rho=500 \mathrm{ppm}$ & 9 & 0.91 \\
$\rho=1000 \mathrm{ppm}$ & 8 & 0.90 \\
\hline
\end{tabular}

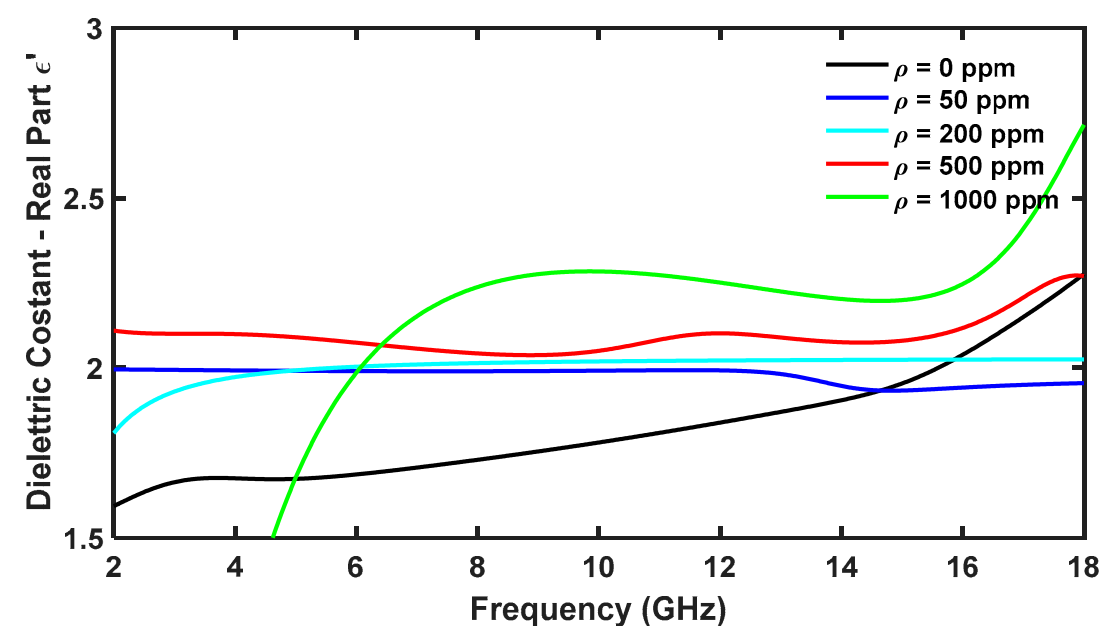

Figure 2. Measured real part $\varepsilon^{\prime}$ of the dielectric constant as a function of the frequency $f$ for different water concentrations $\rho$ in diesel.

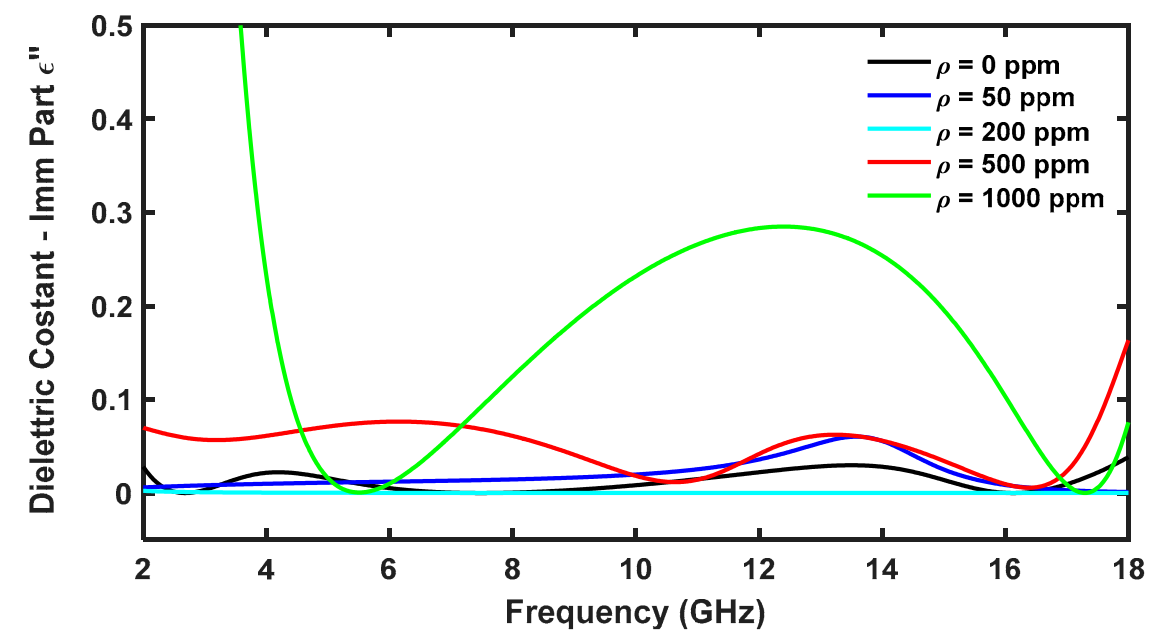

Figure 3. Measured imaginary part $\varepsilon^{\prime \prime}$ of the dielectric constant as a function of the frequency $f$ for different water concentrations $\rho$ in diesel.

It is worth observing that the real part $\varepsilon^{\prime}$ increases as the water concentration increases in a wide frequency range, $f=8-13 \mathrm{GHz}$. To obtain reference values for the ad hocdesigned water-diesel fuel blend SIW applicator, we directly considered the SPEAG DAK 3.5 probe-N9927A VNA-measured characteristics. In particular, by choosing different frequencies, e.g., $f=9,10,11,12,13 \mathrm{GHz}$, different sensing characteristics, i.e., regression curves, can be drawn, as reported in Figure 4 . At these frequencies, a direct proportionality between the water concentration $\rho$ and the real part $\varepsilon^{\prime}$ occurs. Therefore, they are of interest for sensing applications. On the contrary, the frequencies $f<7 \mathrm{GHz}$ or $f>14 \mathrm{GHz}$ are not considered. The characteristics are quite similar, even if with a different coefficient of 
determination $R^{2}$, indicating the proportionate amount of variation in the response variable explained by the independent variable in the linear regression model. We underline that this preliminary investigation has been performed to roughly identify a frequency range where the variation in the complex dielectric constant with water concentration promises potential applications to be investigated.

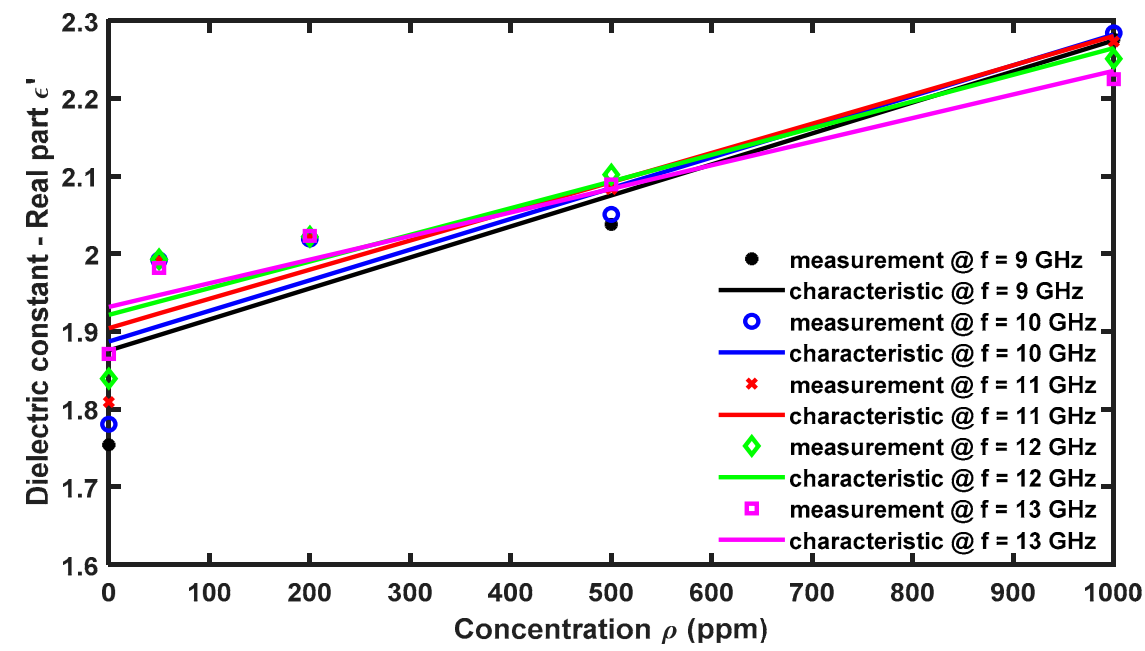

Figure 4. Real part $\varepsilon^{\prime}$ of the dielectric constant, measured with SPEAG DAK 3.5 probe-N9927A VNA, as a function of the water concentration $\rho$ in diesel, for different frequencies.

Table 2 reports the measured sensitivities for the five curves of Figure 4, confirming this observation. The direct proportionality between the real part $\varepsilon^{\prime}$ and the water concentration $\rho$ pave the way to design an ad hoc water in diesel microwave sensor.

Table 2. Sensitivities of the SPEAG DAK 3.5 probe-N9927A VNA as a water-in-fuel sensor for different frequencies.

\begin{tabular}{|c|c|c|}
\hline Frequency (GHz) & Sensitivity $\frac{\Delta \varepsilon_{r}}{\Delta \rho}\left(\times 10^{-3} / \mathrm{ppm}\right)$ & $R^{2}$ \\
\hline 9 & 0.399 & 0.79 \\
\hline 10 & 0.395 & 0.82 \\
\hline 11 & 0.376 & 0.86 \\
\hline 12 & 0.344 & 0.88 \\
\hline 13 & 0.304 & 0.91 \\
\hline
\end{tabular}

\section{Applicator Design}

The aim of the design is to obtain a low cost, planar/low-profile and compact (of few square centimeters) microwave applicator, providing good performance in terms of sensitivity and resolution, even if operating at a single frequency, to be employed in a simple online set-up, for example including a microwave source and an MW power meter.

The employed dielectric substrate is Rogers RT/duroid $5880\left(\varepsilon_{r}=2.2, \tan \delta=0.0009\right)$ of commercial thickness $h_{\text {sub }}=1.575 \mathrm{~mm}$, whereas metallic parts are made of copper $\left(\sigma=5.8 \times 10^{7} \mathrm{~S} / \mathrm{m}\right)$ with thickness $h=0.035 \mathrm{~mm}$.

The design and characterization of the SIW applicator is performed with reference to both the air and water-in-diesel surrounding medium (background). In the case of the water-in-diesel background, the measured complex dielectric constant of Figures 2 and 3 have been considered.

\subsection{Single Slot SIW Applicator in Air}

The first geometry, reporting the main parameters, is shown in Figure 5. The preliminary values of the geometric parameters are reported in Table 3 . The geometry depicted in Figure 5 is obtained considering an SIW guide fed by a microstrip line. The strip line sizes 
$W_{\text {feed }}$ and $L_{\text {feed }}$ are designed to ensure a characteristic impedance $Z_{0}=50 \Omega$ [42]. The vias diameter $d$, the center-center distance $s$, and the other preliminary geometrical values are chosen following [25-29]. The slot ensures the radiation of the EM field and its interaction with the fuel samples.

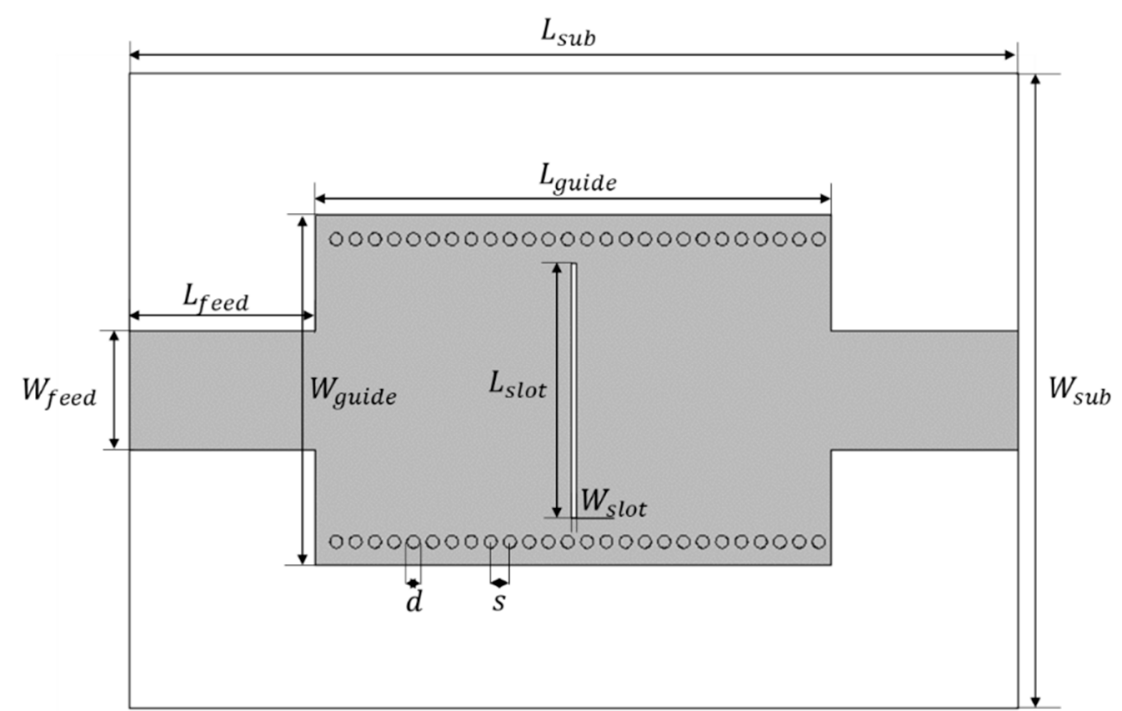

Figure 5. Scheme of the designed single-slot SIW applicator in air.

Table 3. Main geometric parameters of the designed single-slot SIW applicator in air.

\begin{tabular}{ccc}
\hline Parameter & Value & Description \\
\hline$L_{\text {sub }}$ & $35 \mathrm{~mm}$ & Substrate length \\
$W_{\text {sub }}$ & $25 \mathrm{~mm}$ & Substrate width \\
$L_{\text {guide }}$ & $14.3 \mathrm{~mm}$ & SIW length \\
$W_{\text {guide }}$ & $13.8 \mathrm{~mm}$ & SIW width \\
$W_{\text {feed }}$ & $4.7 \mathrm{~mm}$ & Microstrip line width \\
$L_{\text {feed }}$ & $10.35 \mathrm{~mm}$ & Microstrip line length \\
$W_{\text {slot }}$ & $0.3 \mathrm{~mm}$ & Slot width \\
$L_{\text {slot }}$ & $10.05 \mathrm{~mm}$ & Slot length \\
$s$ & $0.75 \mathrm{~mm}$ & Center-center distance of vias \\
$d$ & $0.5 \mathrm{~mm}$ & Vias diameter \\
\hline
\end{tabular}

Figure 6 shows the equivalent circuit of the single-slot SIW applicator [43-45]. The distributed-constants network, modelling the input and output microstrip transmission lines, includes the series impedance $Z=R+j \omega L$ per unit length and the shunt admittance $Y=G+j \omega C$ per unit length. The inductance $L_{S}$ and the capacity $C_{S}$ model the transverse slot $[43,44]$.

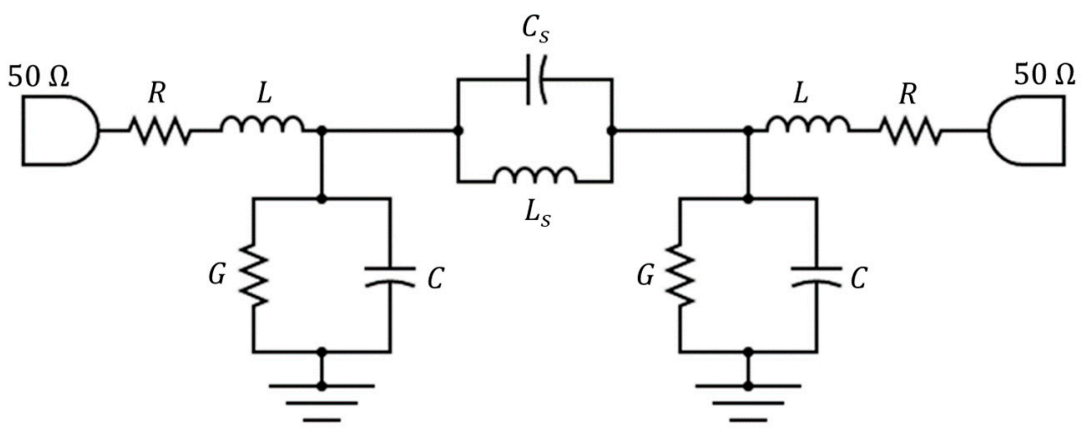

Figure 6. Equivalent circuit of the single-slot SIW applicator. 
Figure 7 shows the distribution of the modulus of the electric field irradiated by the slot in the $x y$ plane, i.e., at the upper metal layer. The discontinuity between the feeding microstrip line and the SIW tends to confine the electric field near to the slot, as in a slotted resonant-like structure, improving the interaction with the fuel samples.
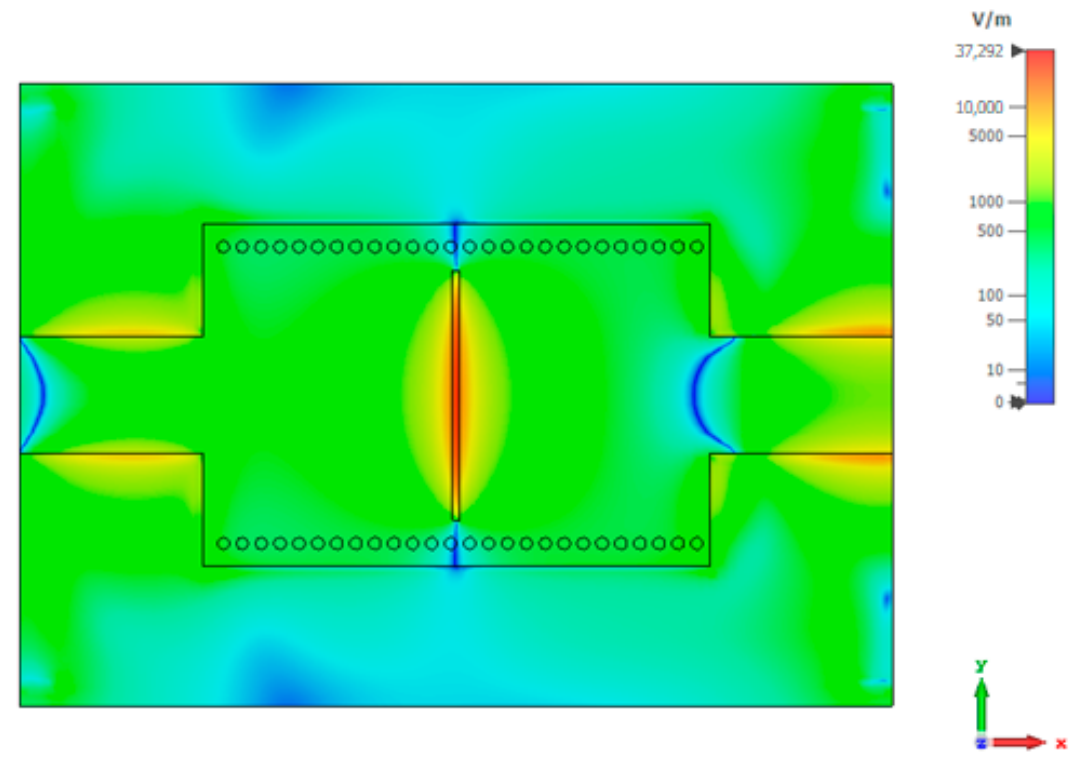

Figure 7. Modulus of the electric field irradiated by the slot in the $x y$ plane, single-slot SIW applicator in air.

The first optimization regards the SIW length $L_{\text {guide }}$. Starting from the preliminary value reported in Table 3, $L_{\text {guide }}=14 \mathrm{~mm}$, larger values have been simulated until $L_{\text {guide }}=20 \mathrm{~mm}$, by considering a change step $\Delta L_{\text {guide }}=2 \mathrm{~mm}$. The extreme of the range $L_{\text {guide }}=20 \mathrm{~mm}$ is arbitrarily fixed to guarantee a high compactness degree.

The modulus of the scattering parameters $S_{11}$ and $S_{21}$ as a function of frequency $f$ for different values of the SIW length $L_{\text {guide }}$ has exhibited a bandwidth increase and an increased impedance matching at the fixed extreme value $L_{\text {guide }}=20 \mathrm{~mm}$. The optimization of the radiating slot is performed with the aim of further improving the device operation. Figure 8 shows the modulus of the scattering parameters $S_{11}$ (solid curves) and $S_{21}$ (dotted curves) as a function of frequency $f$ for different values of the slot width $W_{\text {slot }}$. As the slot width becomes smaller, a better impedance matching can be observed. However, the extreme $W_{\text {slot }}=0.2 \mathrm{~mm}$ was arbitrarily fixed to allow a sufficient interaction between measurand background and EM field. Many other optimizations were performed by varying slot length $L_{\text {slot }}$, center-center vias distance $s$, and vias diameter $d$, but the performances were worse.

\subsection{Cross Slot SIW Applicator in Air}

The SIW applicator geometry is modified with the aim to improve the sensing performances. Two half geometries, allowing half mode behavior, of the previous applicator are placed in close position and coupled via a gap, named the horizontal slot. The further, horizontal, slot is designed to enhance the interaction between the EM field and the fuel samples. The new geometry, reporting the main parameters, is shown in Figure 9. The preliminary values of the geometric parameters are reported in Table 4. For this SIW applicator, asymmetric input and output microstrip lines are designed. This is justified by considering that it is similar to the composition of two half-mode structures.

Figure 10 shows the equivalent circuit of the cross-slot SIW applicator [43-45]. The equivalent circuit is composed by two circuits similar to the previous one. Each of them refers to one of the two half-mode structures. The proximity coupling is modelled via the mutual inductance of $M_{12}$, the effect of the cut on the half-mode structure is modeled by a properly high value load impedance $Z_{L}$. 
The SIW length is again set at $L_{\text {guide }}=20 \mathrm{~mm}$. The optimization has regarded the parameters of slot width $W_{\text {slot }}$, slot length $L_{\text {slot }}$, and gap width $W_{\text {gap }}$.

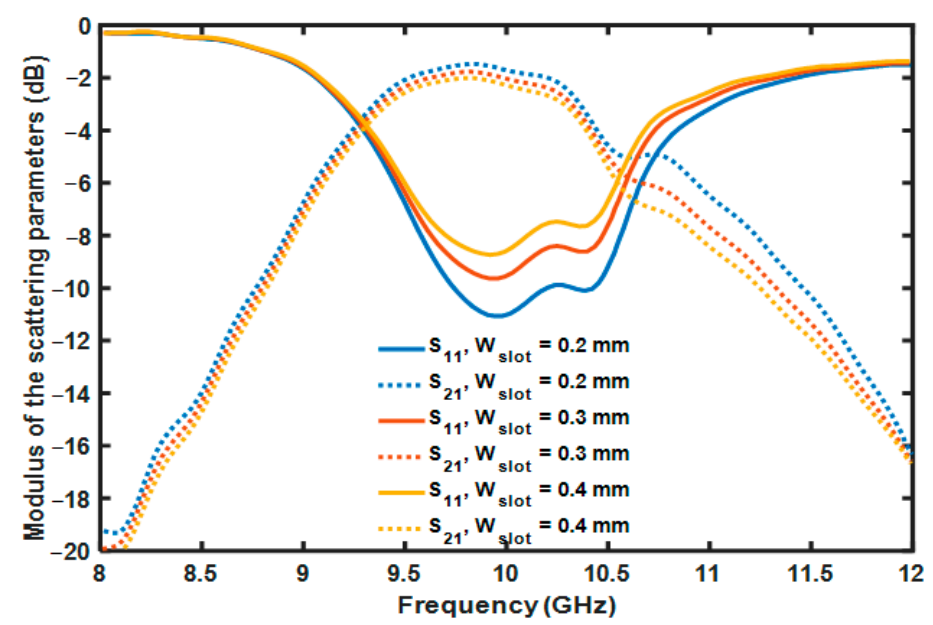

Figure 8. Modulus of the scattering parameters $S_{11}$ (solid curves) and $S_{21}$ (dotted curves) as a function of frequency $f$ for different values of the slot width $W_{\text {slot }}$.

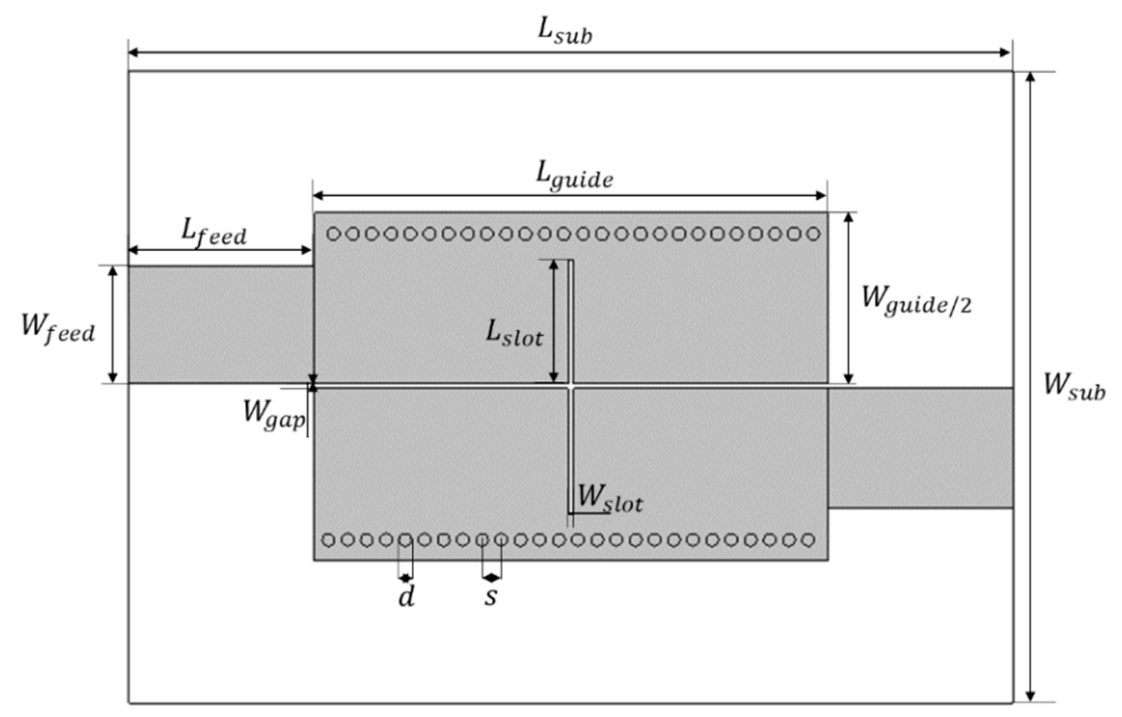

Figure 9. Scheme of the designed cross-slot SIW applicator.

Table 4. Main geometric parameters of the designed cross-slot SIW applicator.

\begin{tabular}{ccc}
\hline Parameter & Value & Description \\
\hline$L_{\text {sub }}$ & $35 \mathrm{~mm}$ & Substrate length \\
$W_{\text {sub }}$ & $25 \mathrm{~mm}$ & Substrate width \\
$L_{\text {guide }}$ & $20.3 \mathrm{~mm}$ & SIW length \\
$W_{\text {guide }}$ & $6.9 \mathrm{~mm}$ & SIW width \\
$W_{\text {feed }}$ & $4.7 \mathrm{~mm}$ & Microstrip line width \\
$L_{\text {feed }}$ & $7.5 \mathrm{~mm}$ & Microstrip line length \\
$W_{\text {slot }}$ & $0.3 \mathrm{~mm}$ & Slot width \\
$L_{\text {slot }}$ & $4 \mathrm{~mm}$ & Slot length \\
$W_{\text {gap }}$ & $0.3 \mathrm{~mm}$ & Gap width \\
$s$ & $0.75 \mathrm{~mm}$ & Center-center distance of vias \\
$d$ & $0.5 \mathrm{~mm}$ & Vias diameter \\
\hline
\end{tabular}




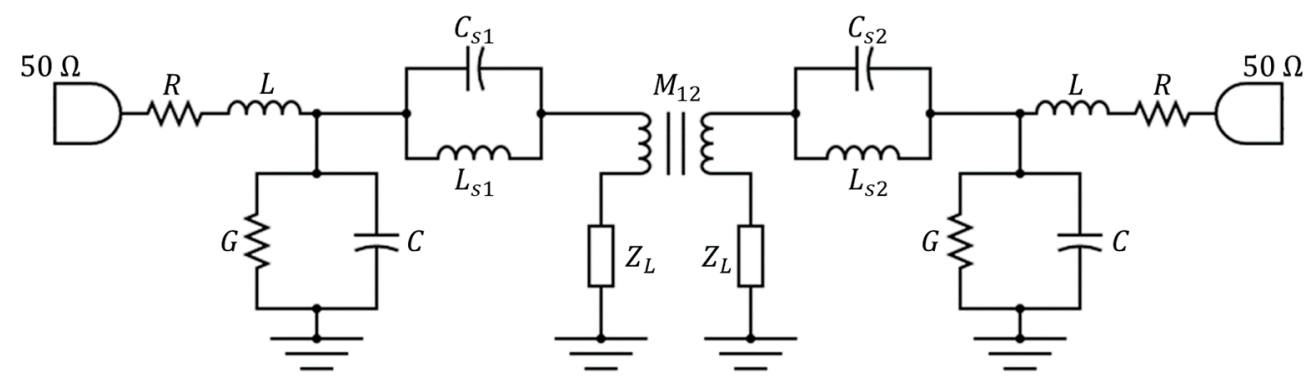

Figure 10. Equivalent circuit of the cross slot SIW applicator.

For the slot width $W_{\text {slot }}$, the parametric investigation is performed in the range $W_{\text {slot }}=0.2-0.4 \mathrm{~mm}$. The modulus of the scattering parameters $S_{11}$ and $S_{21}$ as a function of the frequency $f$ for different values of slot width $W_{\text {slot }}$ is simulated. As the slot width $W_{\text {slot }}$ decreases, the impedance matching increases. The best value is $W_{\text {slot }}=0.2 \mathrm{~mm}$. This value is a trade-off. A narrower slot is not investigated, as previously discussed in Section 3.1. Moreover, good impedance matching with $\left|S_{11}\right|=-22 \mathrm{~dB}$ at the frequency of $f=9.6 \mathrm{GHz}$ is reached. A further decrease in the length of $W_{\text {slot }}$ is not interesting and could cause an interaction reduction with the background.

The gap width $W_{\text {gap }}$ is varied in the range of $W_{\text {gap }}=0.2-0.4 \mathrm{~mm}$. Figure 11 shows the modulus of the simulated scattering parameters $S_{11}$ (solid curves) and $S_{21}$ (dotted curves) as a function of the frequency $f$ for different values of gap width $W_{\text {gap }}$. Additionally, the gap width modifies the applicator impedance matching. The best value is $W_{g a p}=0.2 \mathrm{~mm}$, ensuring the maximum transmission bandwidth and the minimum scattering parameter modulus $\left|S_{11}\right|$. The impedance matching with $\left|S_{11}\right|=-23 \mathrm{~dB}$ at the frequency $f=9.6 \mathrm{GHz}$ is obtained.

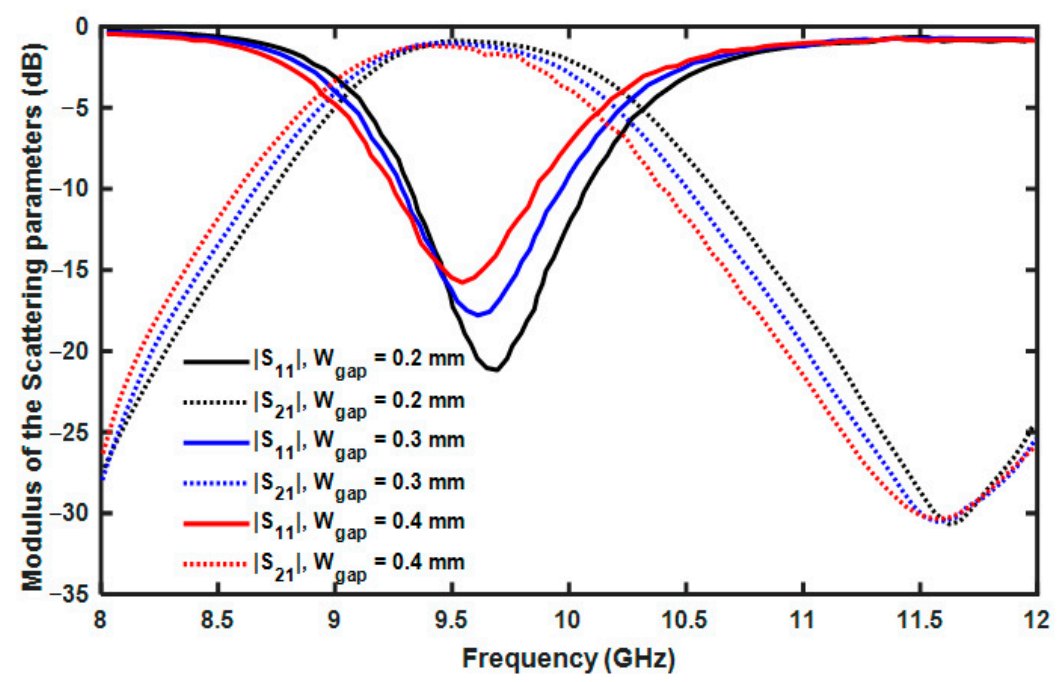

Figure 11. Modulus of the simulated scattering parameters $S_{11}$ (solid curves) and $S_{21}$ (dotted curves) as a function of the frequency $f$ for different values of $W_{g a p}$.

The slot length $L_{\text {slot }}$ is varied in the range of $L_{\text {slot }}=4.9-5.3 \mathrm{~mm}$ in order to ensure the maximum interaction between the fuel sample and the sensor. The modulus of the scattering parameters $S_{11}$ and $S_{21}$ as a function of the frequency $f$ has been simulated for different values of $L_{\text {slot }}$. As the slot length $L_{\text {slot }}$ decreases, the impedance matching increases, and the bandwidth becomes larger. The impedance matching with $\left|S_{11}\right|=-19 \mathrm{~dB}$ at the frequency of $f=9.6 \mathrm{GHz}$ is simulated for $L_{\text {slot }}=4.9 \mathrm{~mm}$.

After all the optimizations, the optimal geometrical dimensions for the cross-slot SIW device are reported in Table 5. These values ensure a good impedance matching and the wide bandwidth in the 9-10 GHz range. The device is also compact and low-profile. 
Table 5. Optimized geometric parameters of the designed cross-slot SIW applicator.

\begin{tabular}{ccc}
\hline Parameter & Value & Description \\
\hline$L_{\text {sub }}$ & $35 \mathrm{~mm}$ & Substrate length \\
$W_{\text {sub }}$ & $25 \mathrm{~mm}$ & Substrate width \\
$L_{\text {guide }}$ & $20 \mathrm{~mm}$ & SIW length \\
$W_{\text {guide } / 2}$ & $6.9 \mathrm{~mm}$ & Half SIW width \\
$W_{\text {feed }}$ & $4.7 \mathrm{~mm}$ & Microstrip line width \\
$L_{\text {feed }}$ & $7.5 \mathrm{~mm}$ & Microstrip line length \\
$W_{\text {slot }}$ & $0.2 \mathrm{~mm}$ & Slot width \\
$L_{\text {slot }}$ & $4.9 \mathrm{~mm}$ & Slot length \\
gap & $0.2 \mathrm{~mm}$ & Gap distance \\
s & $0.75 \mathrm{~mm}$ & Center-center distance of vias \\
$d$ & $0.5 \mathrm{~mm}$ & Vias diameter \\
\hline
\end{tabular}

\section{Simulation of Cross-Slot SIW Applicator as Sensor Water-in-Diesel Background}

To evaluate the cross-slot SIW applicator performances as a water-in-fuel sensor, the measured dielectric constants of the five samples were imported into the simulation CST Studio Suite ${ }^{\circledR}$ software. A similar investigation to that reported in Section 3 was performed, showing that the same SIW structure could be employed with a water-in-diesel background, allowing a promising performance without further refinement. In other words, the dielectric constant of air and the real part $\varepsilon^{\prime}$ of the diesel dielectric constant at the considered frequencies $f$ are sufficiently close.

In fact, Figure 12 illustrates the modulus of the scattering parameters $S_{11}$ (solid curves) and $S_{21}$ (dotted curves) as a function of the frequency $f$ for air (black curve) and pure diesel (blue curve) backgrounds. The impedance matching with $\left|S_{11}\right|=-18 \mathrm{~dB}$ at the frequency $f=9.5 \mathrm{GHz}$ for the diesel background is good enough.

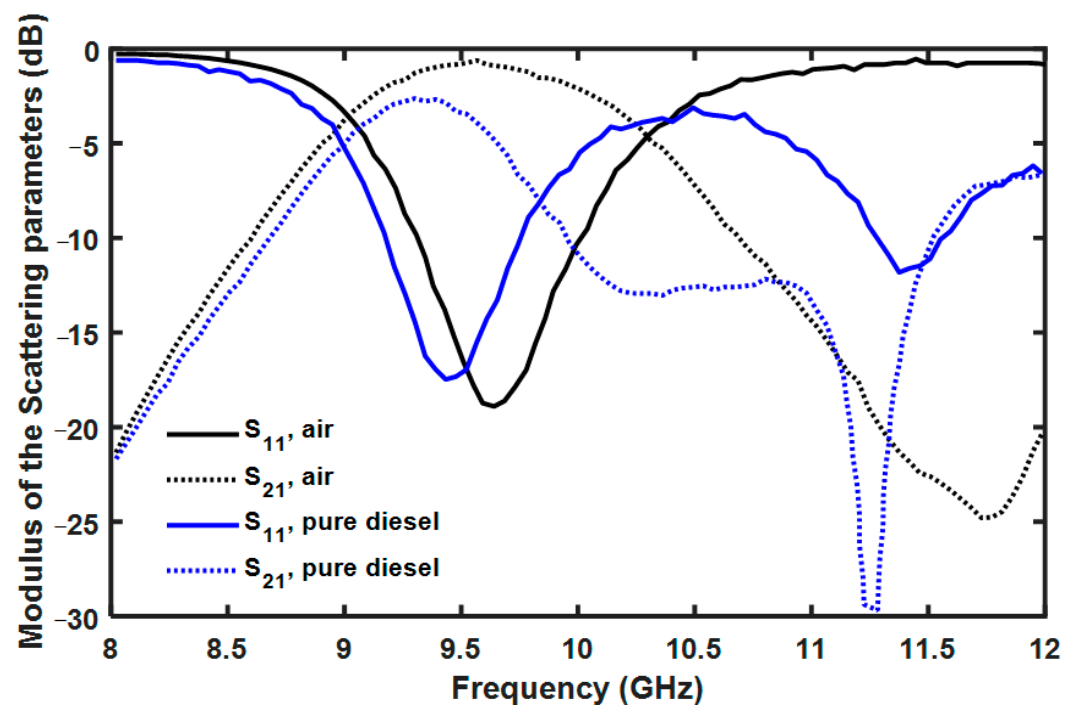

Figure 12. Cross-slot SIW applicator. Modulus of the simulated scattering parameters $S_{11}$ (solid curves) and $S_{21}$ (dotted curves) as a function of the frequency $f$ for air (black curves) and pure diesel (blue curves) backgrounds.

The percentage change on the modulus of the scattering parameter $S_{21}$, obtained by simulating the diesel sample (i) in contact and (ii) placed at the distance $d_{\text {air }}=0.1 \mathrm{~mm}$ from the top metallic layer, is below $\Delta S_{21}=9 \%$. However, the distance $d_{\text {air }}$ can be eliminated in practical application after an easy mechanical optimization.

The percentage change in the modulus of the scattering parameter $S_{21}$ obtained by simulating the diesel sample in contact with the top metallic layer and the radiating slots (iii) filled with diesel and (iv) filled with air is of the order of $\Delta S_{21}=1.3 \%$. Additionally, this error can be eliminated by a direct contact of the applicator with diesel flux. 
Figure 13a shows the modulus of the simulated scattering parameter $S_{21}$ as a function of the frequency $f$ for the five different water concentrations. Figure $13 \mathrm{~b}$ is a magnified view of the matching frequency $f=9.5 \mathrm{GHz}$. It shows that, as the water concentration increases, the modulus of the scattering parameter $S_{21}$ decreases. The variation is quite linear. The values of the modulus of the scattering parameter $S_{21}$ for the five water concentrations at frequency $f=9.2 \mathrm{GHz}$ are listed in Table 6 .

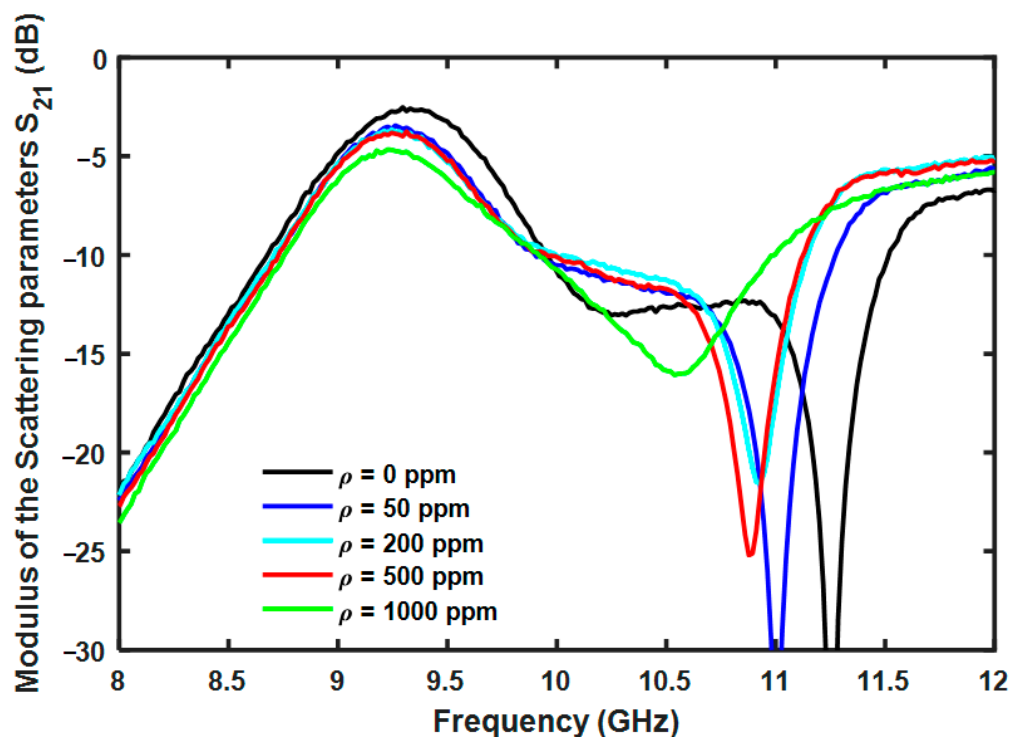

(a)

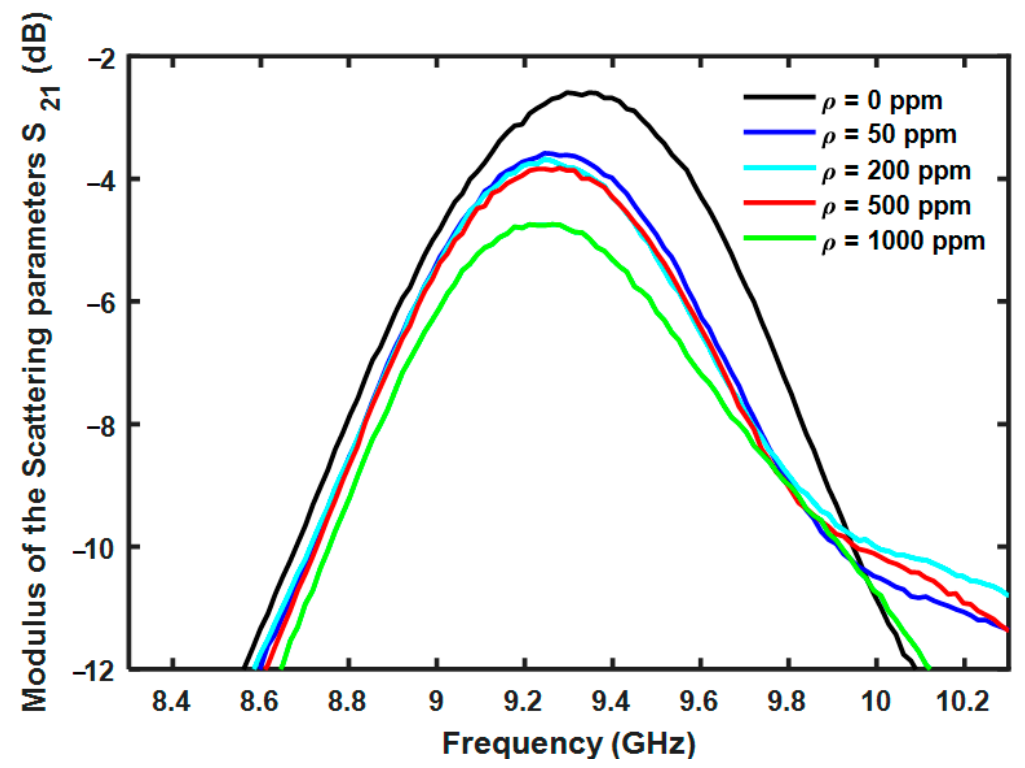

(b)

Figure 13. Cross-slot SIW applicator. (a) Modulus of the simulated scattering parameters $S_{21}$ as a function of the frequency $f$ for different water concentrations. (b) Zoom around $f=8.3-10.3 \mathrm{GHz}$.

Table 6. Cross-slot SIW. Modulus of the simulated scattering parameter $S_{21}$ for the five water concentrations at frequency $f=9.2 \mathrm{GHz}$.

\begin{tabular}{cc}
\hline Water Concentration $\rho(\mathbf{p p m})$ & $\left|S_{21}\right| @ 9.2 \mathbf{~ G H z}(\mathbf{d B})$ \\
\hline 0 & -3.033 \\
50 & -3.718 \\
200 & -3.827 \\
500 & -3.930 \\
1000 & -4.778 \\
\hline
\end{tabular}


The simulated sensor sensitivity can be calculated as

$$
\frac{\Delta\left|S_{21}\right|}{\Delta \rho}=1.39 \mathrm{mdB} / \mathrm{ppm} @ 9.2 \mathrm{GHz}
$$

The coefficient of determination is $R^{2}=0.85$, which is quite good.

\section{Cross-Slot SIW Applicator Characterization, Air Background}

The cross-slot SIW applicator was constructed and characterized. Figure 14 shows the fabricated device.

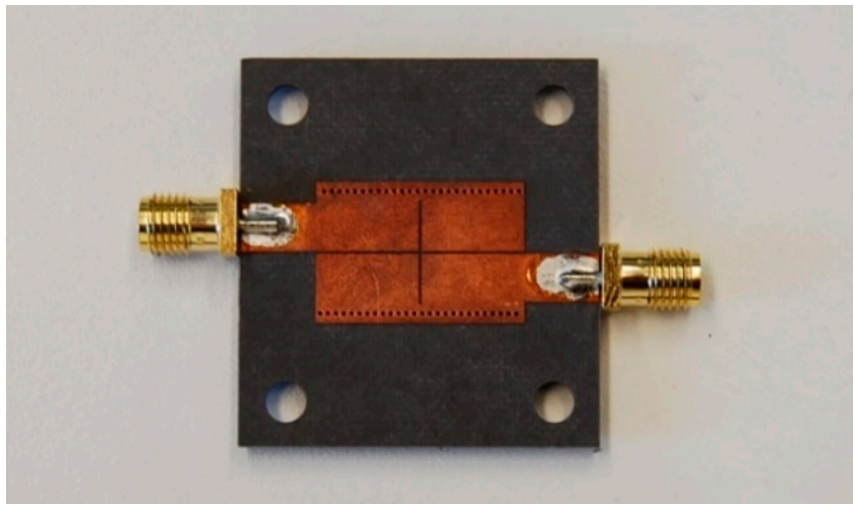

Figure 14. Constructed cross-slot SIW applicator.

The cross-slot SIW applicator was characterized with air as the background, i.e., without considering the fuel sample to be detected, with the VNA Keysight FieldFox. The measured modulus of the scattering parameters $S_{11}$ and $S_{21}$ as a function of the frequency $f$ is shown in Figure 15 (solid curves) and compared with the simulated parameters (dotted curves). The results are in agreement with the simulations. A right shift of about $\Delta f=0.5 \mathrm{GHz}$ can be seen for both $S_{11}$ and $S_{21}$ curves. This behavior can be caused by the fabrication tolerance leading to a little mismatch between the geometric dimensions of the fabricated device and the nominal/optimized ones reported in Table 5.

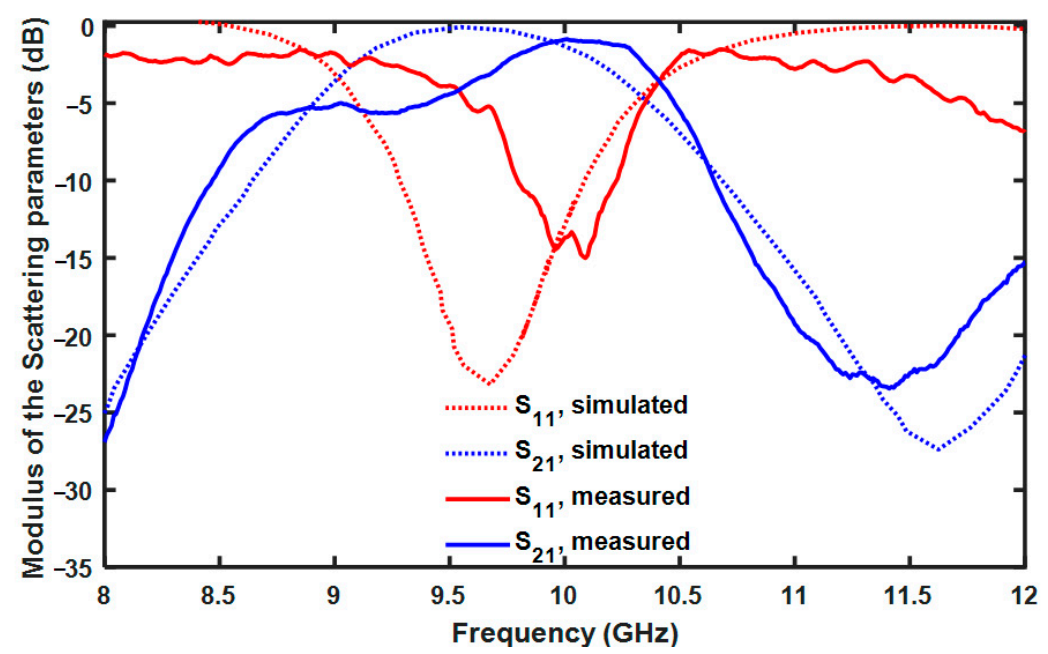

Figure 15. Cross-slot SIW. Modulus of the scattering parameters $S_{11}$ and $S_{21}$ as a function of the frequency $f$ for measured (solid curves) and simulated (dotted curves).

\section{Cross-Slot SIW Applicator Characterization, Water-in-Diesel Background}

The same fuel samples, characterized in Section 2 and simulated in Section 4, were used for testing the cross-slot SIW applicator as a water-in-fuel sensor. The bag containing 
the fuel samples is constituted by polyethylene. Figure 16 shows measurements proving that it can be considered transparent, allowing complete radiating field transmission, and does not affect the water-in-diesel characterization.

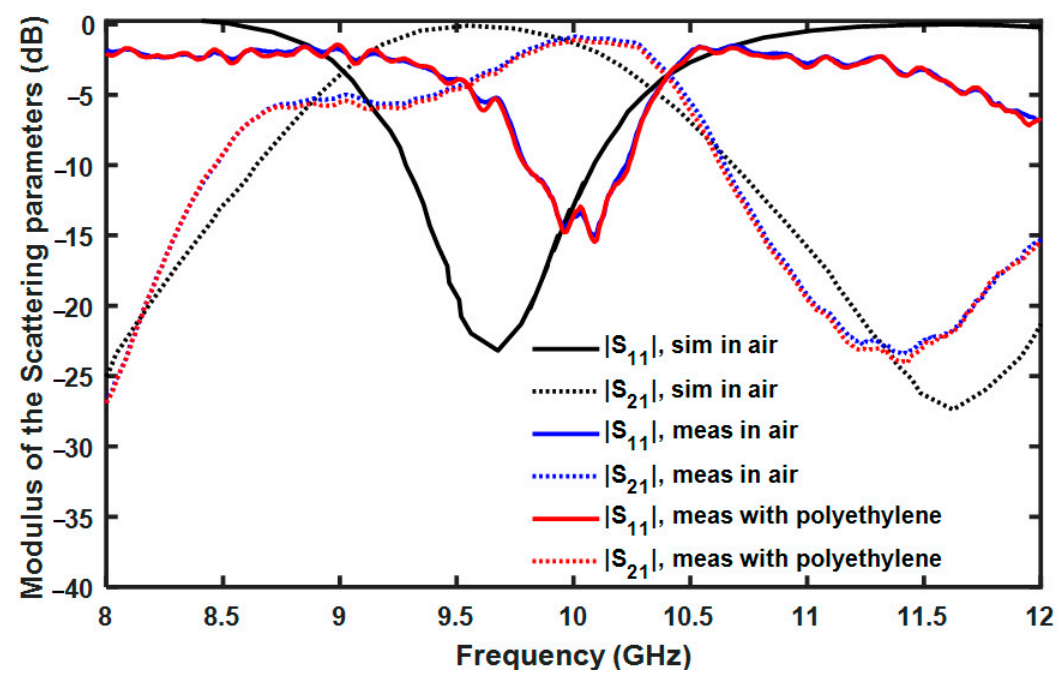

Figure 16. Cross-slot SIW. Modulus of the scattering parameters $S_{11}$ (solid curves) and $S_{21}$ (dotted curves) as a function of the frequency $f$ measured in air (blue curves), measured with polyethylene (red curve), and simulated (black curves).

The complete measurement set-up is shown in Figure 17a. It is composed by the VNA Keysight FieldFox, connected to the constructed cross-slot SIW applicator. Figure 17b shows the plastic bag as transparent at microwave frequencies and placed on the applicator. Its stability is ensured by an appropriate support.

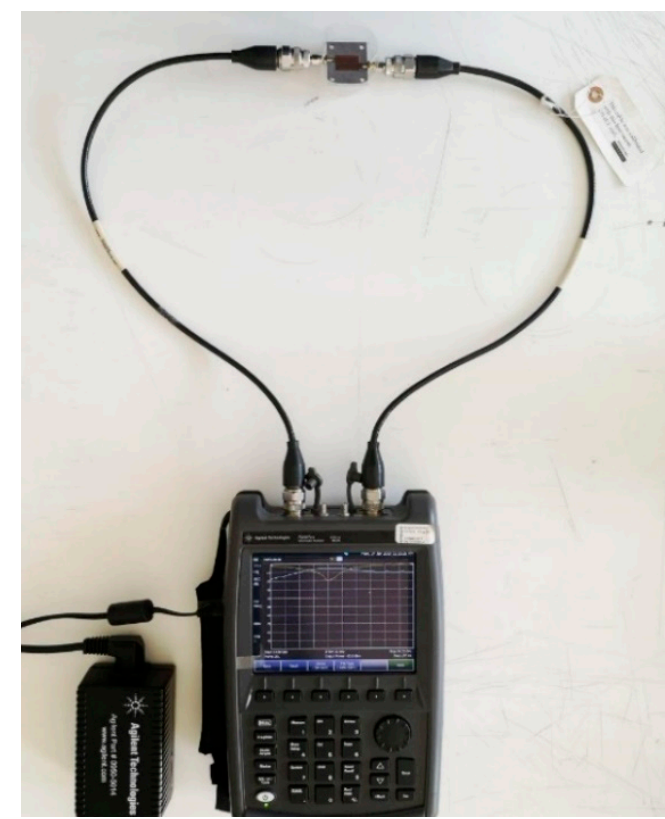

(a)

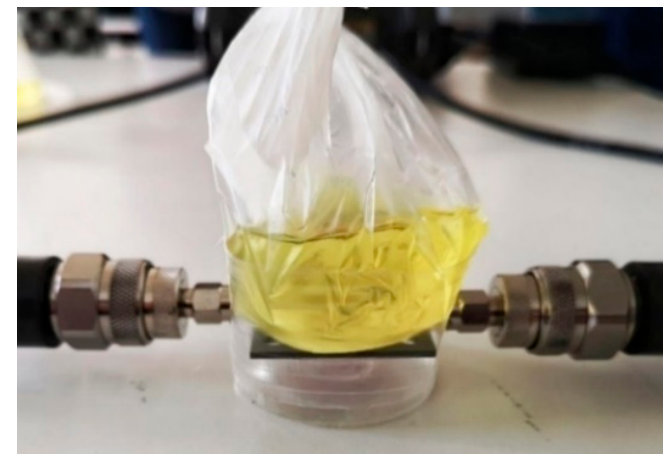

(b)

Figure 17. (a) Measurement set-up using the Keysight VNA N9927A FieldFox and the constructed cross-slot SIW applicator as a water-in-fuel sensor; (b) magnified view of one of the measured fuel samples.

Figure 18a shows the measured modulus and Figure 18b the measured phase of the scattering parameter $S_{11}$ as a function of the frequency, for the five different water 
concentrations $\rho$. These curves do not allow us to easily obtain a sensing characteristic since no change proportional with the water concentration is observed.

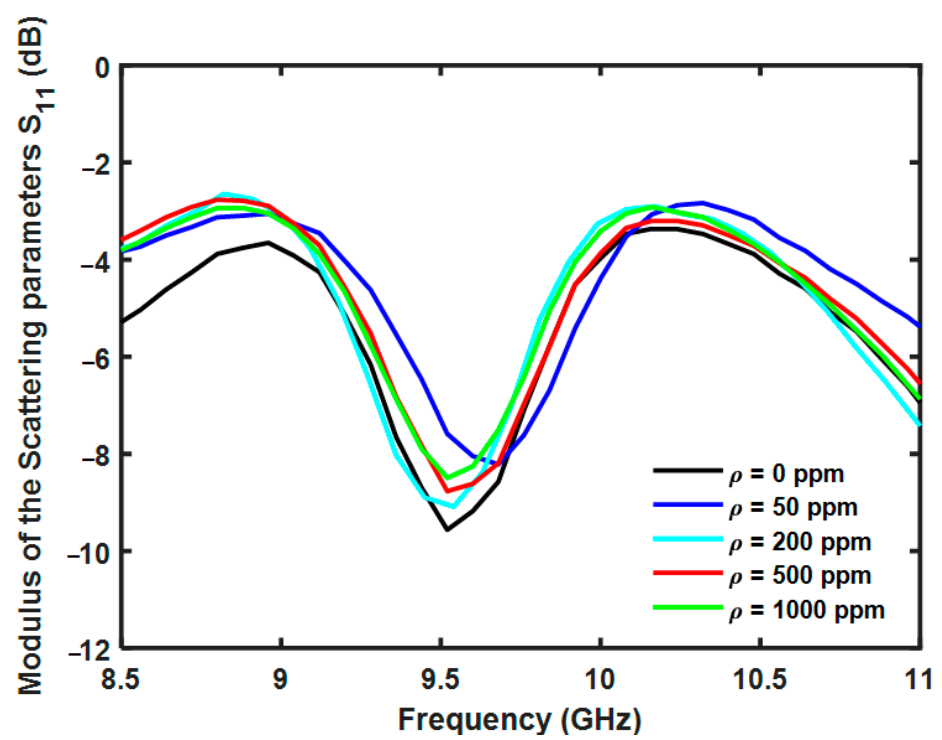

(a)

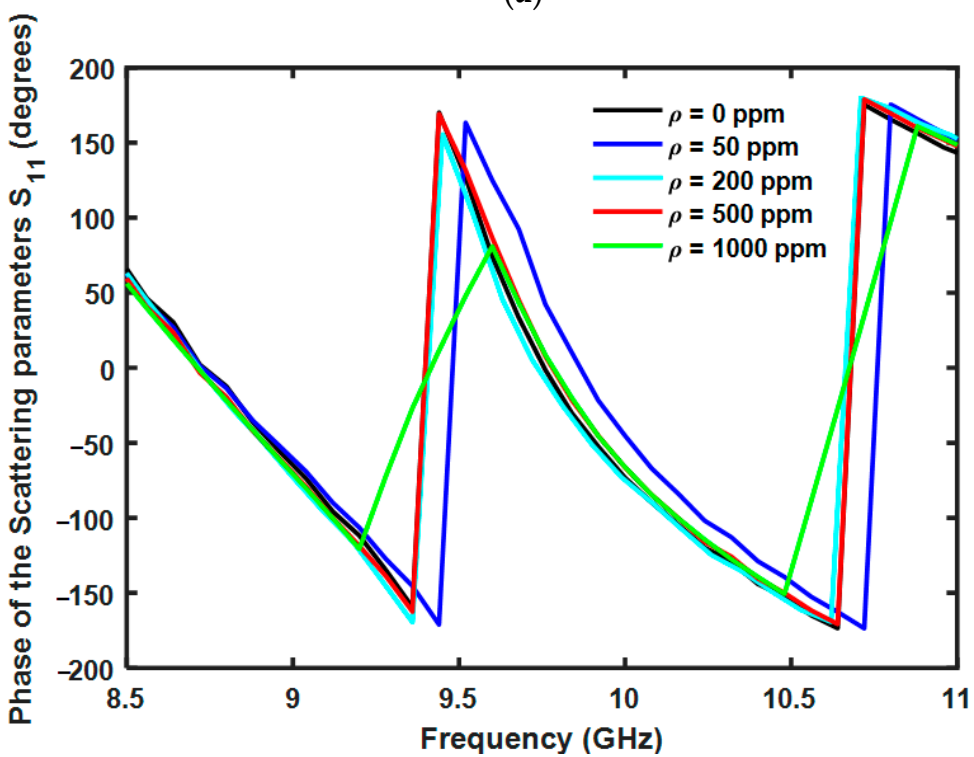

(b)

Figure 18. (a) Measured modulus of the scattering parameter $S_{11}$ as a function of the frequency and (b) measured phase of the scattering parameter $S_{11}$ as a function of the frequency for the five different water concentrations $\rho$.

Figure 19a shows the measured modulus and Figure 19b the measured phase of the scattering parameter $S_{21}$ as a function of the frequency $f$ for the five different water concentrations $\rho$. As expected, no $S_{21}$ phase shift can be observed with variations in water concentration. On the contrary, the measured modulus varies quite linearly, as predicted by simulations. It is affected by the radiated power interacting with the sample, which allows the sensor operation. As for the simulated parameters of Figure 15, the modulus of the scattering parameter $S_{21}$ decreases as the water concentration increases, showing an inverse proportionality.

Table 7 reports the values of the measured modulus of the scattering parameter $S_{21}$ for the different concentrations at a frequency of $f=9.76 \mathrm{GHz}$, where the $\left|S_{21}\right|$ is maximized for all the five curves. 


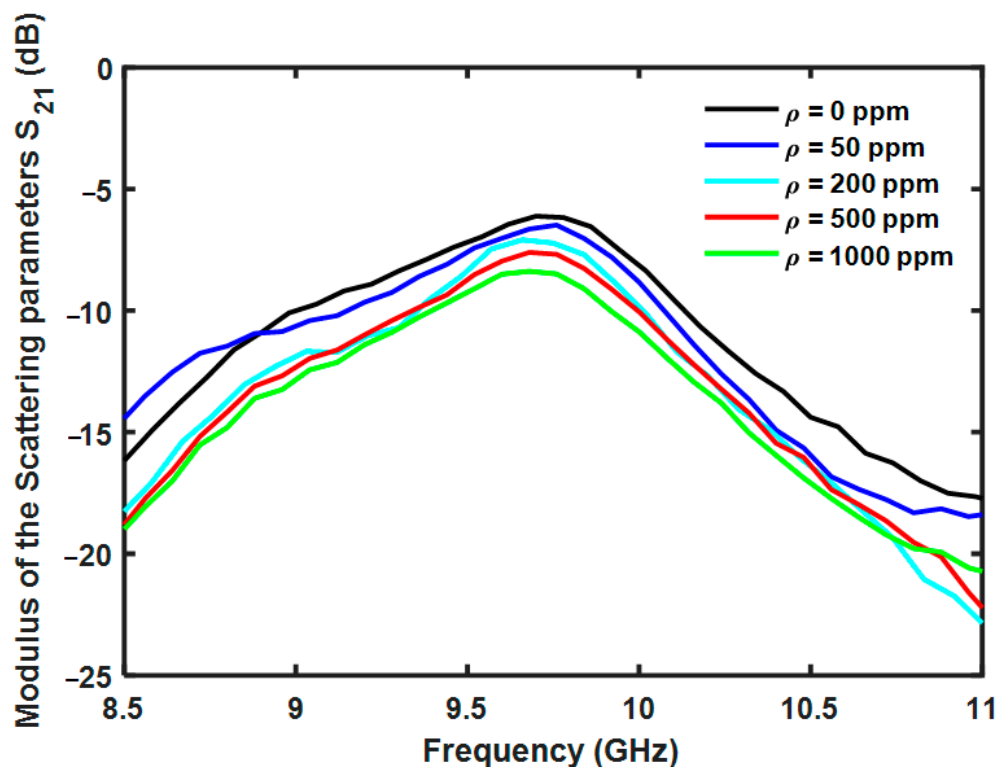

(a)

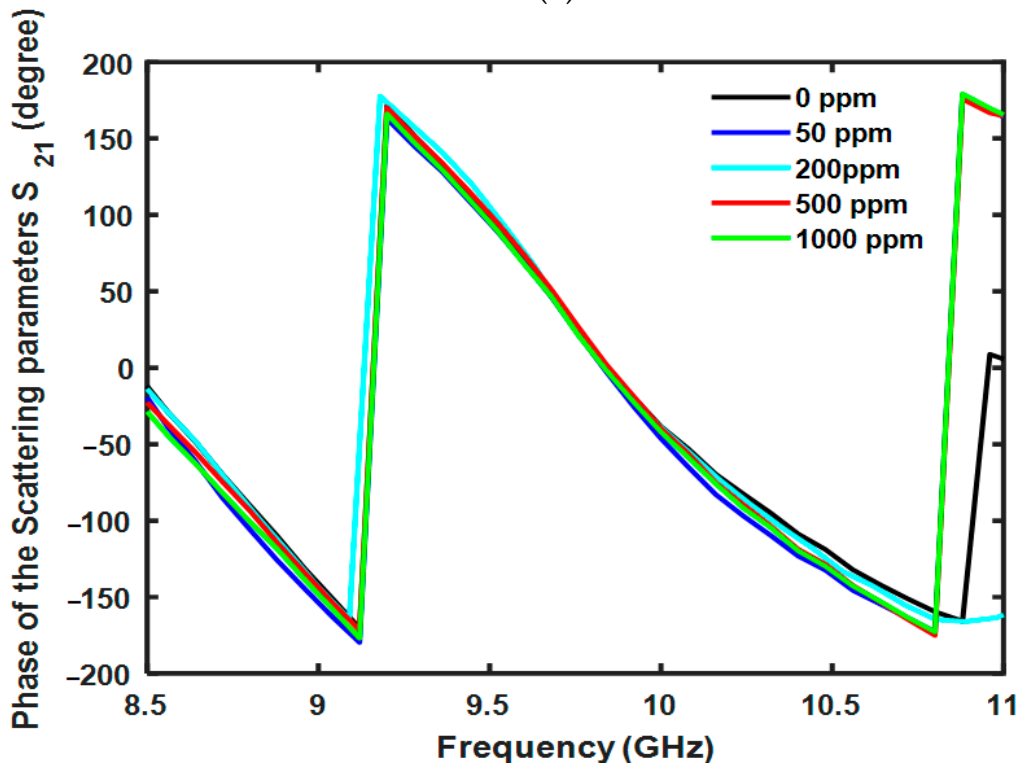

(b)

Figure 19. (a) Measured modulus of the scattering parameter $S_{21}$ as a function of the frequency and (b) measured phase of the scattering parameter $S_{21}$ as a function of the frequency for the five different water concentrations $\rho$.

Table 7. Measured modulus of the scattering parameter $S_{21}$ for the five water concentrations at a frequency of $f=9.76 \mathrm{GHz}$.

\begin{tabular}{cc}
\hline Water Concentration $\rho(\mathbf{p p m})$ & $\left|S_{21}\right| @ 9.76 \mathbf{G H z}(\mathbf{d B})$ \\
\hline 0 & -6.17 \\
50 & -6.48 \\
200 & -7.21 \\
500 & -7.68 \\
1000 & -8.49 \\
\hline
\end{tabular}


Figure 20 shows the measured modulus of the scattering parameter $S_{21}$ as a function of the water concentration. The proportionality is quite linear, so it is possible to calculate the sensitivity as

$$
\frac{\Delta\left|S_{21}\right|}{\Delta \rho}=1.42 \mathrm{mdB} / \mathrm{ppm} @ 9.76 \mathrm{GHz}
$$

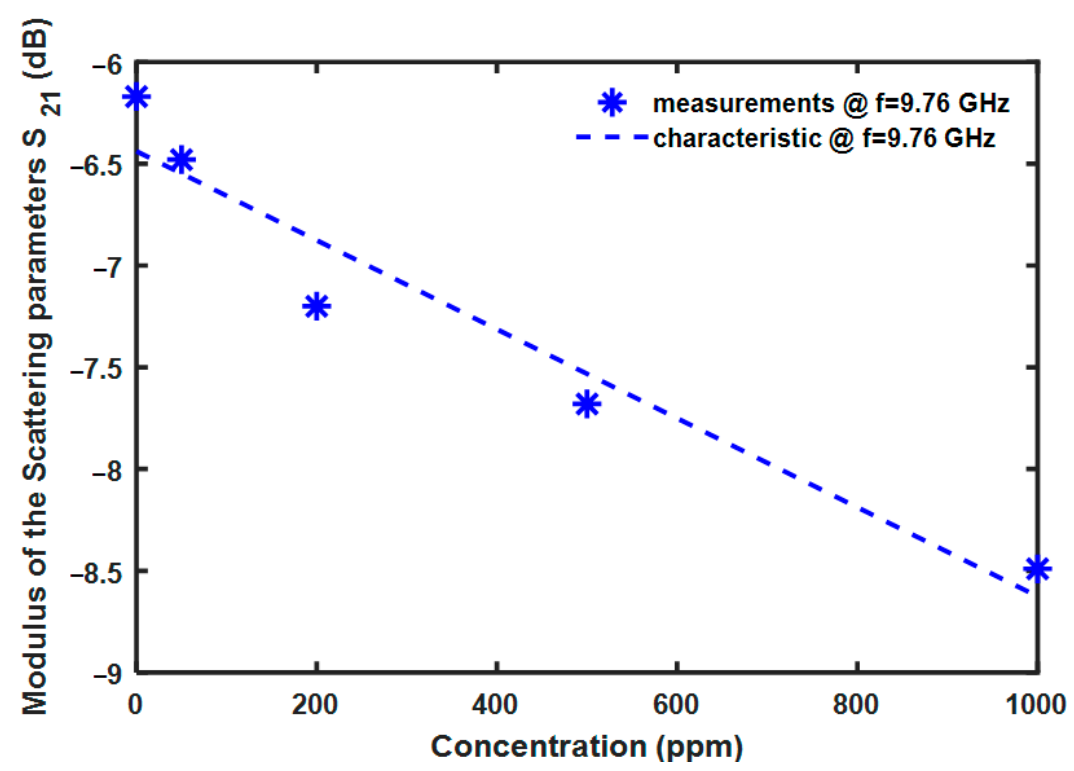

Figure 20. Measured modulus of the scattering parameters $S_{21}$ as a function of water concentration $\rho$ at frequency $f=9.76 \mathrm{GHz}$.

The coefficient of determination is $R^{2}=0.94$, which is in excellent agreement with the simulation illustrated in Section 4. Considering the VNA N9927A resolution $\Delta S_{21}=0.01 \mathrm{~dB}$, the proposed set-up is able to measure a minimum variation in water concentration of $\Delta \rho \approx 7 \mathrm{ppm}$ [41]. The SIW applicator is intriguing for its compactness and performances even when compared with the literature $[14,15,22]$. It could be employed with a single frequency source and an MW power meter in order to obtain an online and low-cost system for diesel quality detection.

The response of the microwave sensor is practically immediate due to the instantaneous interaction of the microwave with the sample. It is worth noting that a potential industrial application for on-time/online measurement could be feasible if the water-indiesel solution flowed in a microwave-transparent tube, in contact with the sensor like the bag used in this paper. In this case, the tube walls should be continuously washed and in contact with the flow to be monitored, thus allowing an instantaneous sensor response.

The influence of temperature on the applicator response is not significant for relatively large changes. In fact, the thermal expansion causes a negligible variation in the sensor size and, as a consequence, a negligible variation in the chosen resonant frequency. This slight variation does not affect the applicator performance since it can operate over the wide frequency range of $f=9-11 \mathrm{GHz}$. Due to the temperature dispersion of the complex dielectric constant of the samples, a calibration could be required for large temperature changes.

The main limitation of the proposed applicator is the low selectivity. Generally, microwave sensors are characterized by a low selectivity, since they are based on the dielectric constant variation of the measured sample. Dielectric constant variation can depend on a number of potential contaminants/concentrations for a given wavelength. However, water contamination is the predominant one occurring in the diesel production/supply chain, and the proposed microwave monitoring is interesting in practical application.

Table 8 reports the comparison between the proposed applicator and the literature results. The proposed sensor exhibits the best sensitivity $\Delta\left|S_{21}\right| / \Delta \rho[14,15,22]$. 
Table 8. Comparison between this work's results and literature results.

\begin{tabular}{cc}
\hline References & Sensitivity $\frac{\Delta\left|S_{21}\right|}{\Delta \rho}(\mathrm{mdB} / \mathrm{ppm})$ \\
\hline$[14]$ & 0.4 \\
{$[15]$} & 0.6 \\
{$[22]$} & 0.0872 \\
This work & 1.42 \\
\hline
\end{tabular}

\section{Conclusions}

In this paper, a water-in-diesel sensor based on an SIW microwave applicator has been designed, constructed, and characterized. This characterization has confirmed the simulated performances in terms of bandwidth and impedance matching. Five watercontaminated fuel samples have been characterized in terms of dielectric constant frequency dispersion with a SPEAG DAK 3.5 probe. The same samples were detected with the designed SIW applicator allowing a water-in-diesel monitoring with a sensitivity of $\Delta\left|S_{21}\right| / \Delta \rho=1.42 \mathrm{mdB} / \mathrm{ppm}$ at a frequency of $f=9.76 \mathrm{GHz}$ with a coefficient of determination $R^{2}=0.94$. The minimum variation in water concentration with the proposed set-up is $\Delta \rho=7 \mathrm{ppm}$. The applicator is interesting because it is low-cost and low-profile, and it could be employed with a single frequency source and an MW power meter.

Author Contributions: Conceptualization, investigation, and methodology, A.M.L., V.V.F., V.P., O.L., M.C., A.D.N., F.A., F.P.; writing—original draft preparation, A.M.L., V.V.F.; writing—review and editing, A.M.L., V.V.F., V.P., F.P.; supervision, A.D.N., F.A., F.P.; All authors have read and agreed to the published version of the manuscript.

Funding: The research received no external funding.

Institutional Review Board Statement: Not applicable.

Informed Consent Statement: Not applicable.

Data Availability Statement: Not applicable.

Acknowledgments: This research has been partially developed within the projects POR FESRFSE 20142020 Innonetwork "Sinach-Integrated systems for mininvasive surgical navigation"-n. BLNGWP7; PON R\&I 2014-2020 “New Satellites Generation components-NSG”-Cod. Id. ARS01_01215 NSG; MIUR “Agriculture Green \& Digital-AGREED”, PNR 2015-2020, n. ARS01_00254; H2020-ICT-37-2020 "Photonic Accurate and Portable Sensor Systems Exploiting Photo-Acoustic and Photo-Thermal Based Spectroscopy for Real-Time Outdoor Air Pollution Monitoring-PASSEPARTOUT" n. 101016956.

Conflicts of Interest: The authors declare no conflict of interest.

\section{References}

1. Digman, W. Effects of Fuel Contamination on Corrosion of Aircraft Fuel Systems; SAE Technical Paper; Warrendale, PA, USA, 1962.

2. Atadashi, I.M.; Aroua, M.K.; Abdul Aziz, A.R.; Sulaiman, N.M.N. The effects of water on biodiesel production and refining technologies: A review. Renew. Sustain. Energy Rev. 2012, 16, 3456-3470. [CrossRef]

3. Oliveira, L.C.; Pereira, E.G.; Oliveira, R.C.; Morais, M.R.A.; Lima, A.M.N.; Neff, H. SPR sensor for tampering detection in biofuels. In Proceedings of the 2015 IEEE International Instrumentation and Measurement Technology Conference (I2MTC), Pisa, Italy, 11-14 May 2015.

4. Levitas, B.; Matuzas, J.; Viswanath, G.; Basalingappa, V.; Venkoparao, V. UWB Based Oil Quality Detection. In Proceedings of the 2011 IEEE International Conference on Ultra-Wideband (ICUWB), Bologna, Italy, 14-16 September 2011.

5. Kunte, A.; Kulkarni, S. Experimental investigation of complex permittivity and determination of ethanol content in gasoline. In Proceedings of the 2008 International Conference of Recent Advances in Microwave Theory and Applications, Microwave 2008, Jaipur, India, 21-24 November 2008; pp. 171-174.

6. Kunte, A.; Gaikwad, A. Adulteration Detection in Petroleum Liquids using Stacked Multi Ring Resonator. In Proceedings of the 2018 Third International Conference on Electrical, Electronics, Communication, Computer Technologies and Optimization Techniques (ICEECCOT), Msyuru, India, 14-15 December 2018.

7. Foundazi, A.; Donnell, K.M. Design of a Microstrip Patch Antenna for Microwave Sensing of Petroleum Production Lines. In Proceedings of the 2017 United States National Committee of URSI National Radio Science Meeting (USNC-URSI NRSM), Boulder, CO, USA, 4-7 January 2017. 
8. Lee, C.H.; Jeong, Y.; Ashraf, H. Rectangular Cavity Sensor for Distinguishing between Normal and High-Drivability-Index Gasolines. IEEE Access 2020, 8, 182193-182203. [CrossRef]

9. Kulkarni, S.; Joshi, M.S. Design and Analysis of Shielded Vertically Stacked Ring Resonator as Complex Permittivity Sensor for Petroleum Oils, IEEE Trans. Microw. Theory Tech. 2015, 63, 2411-2417. [CrossRef]

10. Kunte, A.A.; Gaikwad, A.N. Dielectric constant measurement of low loss liquids using stacked multi ring resonator. Sadhana 2018, 43, 1-12. [CrossRef]

11. Eyebe, G.A.; Sama, N.; Boubekeur, N.; Domigue, F. Microwave Sensing Schemes of CPW Resonators Fully Printed on Humidity Sensitive Substrates. IEEE Microw. Wirel. Compon. Lett. 2020, 29, 303-305. [CrossRef]

12. EN 590:2004. Automotive Fuels. Diesel. Requirements and Test Methods, Standard; European Committee for Standardization: Bruxelles, Belgium, 2004.

13. ASTM D1655. Standard Specification for Aviation. Turbine Fuels, Annual Book of ASTM Standards (Section 05); Technical Report; American Society of Testing and Materials (ASTM): West Conshohocken, PA, USA, 2009.

14. Andria, G.; Attivissimo, F.; Di Nisio, A.; D’Aucelli, G.M.; Camporeale, S.M.; Pappalardi, P. Design of a Microwave Sensor for Fuel Quality Monitoring. In Proceedings of the 2018 5th IEEE International Workshop on Metrology for AeroSpace (MetroAeroSpace), Rome, Italy, 20-22 June 2018.

15. Andria, G.; Attivissimo, F.; Di Nisio, A.; Trotta, A.; Camporeale, S.M.; Pappalardi, P. Design of a microwave sensor for measurement of water in fuel contamination. Measurement 2019, 136, 74-81. [CrossRef]

16. Farries, M.; Hayes, N.; Kelley, J.; Tippet, G.; Webb, G.; Tighe, B.; Zhou, K. Optical methods for detecting contamination in jet fuel. In Proceedings of the 2009 IEEE Avionics, Fiber-Optics and Photonics Technology Conference, San Antonio, TX, USA, 22-24 September 2009.

17. Zhang, W.; Webb, D.J.; Carpenter, M.; Williams, C. Measuring water activity of aviation fuel using a polymer optical fiber Bragg grating. In Proceedings of the SPIE 9157, 23rd International Conference on Optical Fibre Sensors, Santander, Spain, 2 June 2014.

18. Zhang, W.; Grice, S.; Sugden, K.; Bennion, I. Free water in fuel sensor using fiber long period grating. In Proceedings of the SPIE 7753, 21st International Conference on Optical Fiber Sensors, Ottawa, ON, Canada, 17 May 2011.

19. Zhang, W.; Webb, D.J.; Lao, L.; Hammond, D.; Carpenter, M.; Williams, C. Water content detection in aviation fuel by using PMMA based optical fiber grating. Sens. Actuators B Chem. 2019, 282, 774-779. [CrossRef]

20. Räikkönen, H.; Oksanen, M. Microwave acoustic sensing of water in hydrocarbon/water solutions. Sens. Actuator A Phys. 1994, 45, 99-101. [CrossRef]

21. Skwarek, V.; Eggers, T. A Low-cost Capacitive Fuel-level and Quality Sensor for Automotive Applications. In Proceedings of the AMA Conferences 2013-SENSOR 2013, Nürnberg, Germany, 14-16 May 2013; pp. 680-685.

22. Xue, Q.; Tang, X.; Li, Y.; Liu, H.; Duan, X. Contactless and Simultaneous Measurement of Water and Acid contaminations in Oil Using a Flexible Microstrip Sensor. ACS Sens. 2020, 5, 171-179. [CrossRef]

23. Liu, H.; Tang, X.; Lu, H.; Xie, W.; Hu, Y.; Xue, Q. An interdigitated impedance microsensor for detection of moisture content in engine oil. Nanotechnol. Precis. Eng. 2020, 3, 75-80. [CrossRef]

24. Khalid, K.; Grozescu, I.V.; Tiong, L.K.; Sim, L.T.; Mohd, R. Water detection in fuel tanks using the microwave reflection technique. Meas. Sci. Technol. 2003, 14, 1905-1911. [CrossRef]

25. Cassivi, Y.; Perregrini, L.; Arcioni, P.; Bressan, M.; Wu, K.; Conciauro, G. Dispersion characteristics of substrate integrated rectangular waveguide. IEEE Microw. Wirel. Compon. Lett. 2002, 12, 333-335. [CrossRef]

26. $\mathrm{Xu}, \mathrm{F}$; $\mathrm{Wu}, \mathrm{K}$. Guided-wave and leakage characteristics of substrate integrated waveguide. IEEE Trans. Microw. Theory Tech. 2005, $53,66-73$.

27. Venanzoni, G.; Mencarelli, D.; Morini, A.; Farina, M.; Prudenzano, F. Review of Substrate Integrated Waveguide Circuits for Beam-Forming Networks Working in X-Band. Appl. Sci. 2019, 9, 1003. [CrossRef]

28. Bozzi, M.; Georgiadis, A.; Wu, K. Review of substrate-integrated waveguide circuits and antennas. IET Microw. Antenna Propag. 2011, 5, 909-920. [CrossRef]

29. Wu, K.; Deslandes, D.; Cassivi, Y. The Substrate Integrated Circuits-A New Concept for High-Frequency Electronics and Optoelectronics. In Proceedings of the TELSKIS 2003, Nis, Serbia and Montenegro, 1-3 October 2003.

30. Bigelli, F.; Mencarelli, D.; Farina, M.; Venanzoni, G.; Scalmati, P.; Renghini, C.; Morini, A. Design and Fabrication of a Dielectricless Substrate-Integrated Waveguide. IEEE Trans. Compon. Packag. Manuf. Technol. 2016, 6, 256-261. [CrossRef]

31. Portosi, V.; Loconsole, A.M.; Prudenzano, F. A Split Ring Resonator-Based Metamaterial for Microwave Impedance Matching with Biological Tissue. Appl. Sci. 2020, 10, 6740. [CrossRef]

32. Mencarelli, D.; Morini, A.; Prudenzano, F.; Venanzoni, G.; Bigelli, B.; Losito, O.; Farina, M. Broadband Single-Layer Slotted Array Antenna in SIW Technology. IEEE Antennas Wirel. Propag. Lett. 2016, 15, 263-265. [CrossRef]

33. Liu, C.; Tong, F. An SIW Resonator Sensor for Liquid Permittivity Measurements at C Band. IEEE Microw. Wirel. Compon. Lett. 2015, 25, 751-753.

34. Losito, O.; Portosi, V.; Venanzoni, G.; Bigelli, F.; Mencarelli, D.; Scalmati, P.; Renghini, C.; Carta, P.; Prudenzano, F. Feasibility Investigation of SIW Cavity-Backed Patch Antenna Array for Ku Band Applications. Appl. Sci. 2019, 9, 1271. [CrossRef]

35. Qi, C.; Jackson, D.R.; Yao, Y.; Chen, J. SIW Microstrip Cavity Resonators with a Sensing Aperture. In Proceedings of the 2019 IEEE Texas Symposium on Wireless and Microwave Circuits and Systems (WMCS), Waco, TX, USA, 28-29 March 2019. 
36. Venanzoni, G.; Mencarelli, D.; Morini, A.; Farina, M.; Angeloni, G.; Renghini, C.; Carta, P.; Potenza, P.; Losito, O.; Mescia, L.; et al. Single Layer Standalone Wideband Substrate Integrated Waveguide Directional Coupler. Microw. Opt. Technol. Lett. 2014, 56, 1141-1144. [CrossRef]

37. Castellano, T.; Losito, O.; Mescia, L.; Chiapperino, M.A.; Venanzoni, G.; Mencarelli, D.; Angeloni, G.; Renghini, C.; Carta, P.; Prudenzano, F. Feasibility Investigation of Low Cost Substrate Integrated Waveguide (SIW) Directional Couplers. Prog. Electromagn. Res. B 2014, 59, 31-44. [CrossRef]

38. Chiapperino, M.A.; Losito, O.; Castellano, T.; Venanzoni, G.; Mescia, L.; Angeloni, G.; Renghini, C.; Carta, P.; Potenza, P.; Prudenzano, F. Dual-Band Substrate Integrated Waveguide Resonator Based on Sierpinski Carpet. Prog. Electromagn. Res. C 2015, 57, 1-12. [CrossRef]

39. Venanzoni, G.; Mencarelli, D.; Morini, A.; Farina, M.; Losito, O.; Prudenzano, F. Compact Double-Layer Substrate Integrated Waveguide Magic Tee for X-Band Applications. Microw. Opt. Technol. Lett. 2016, 58, 932-936. [CrossRef]

40. SPEAG. DAK Professional Handbook V 1.10. August 2013.

41. Keysight. FieldFox Handheld Analyzers 4/6.5/9/14/18/26.5/32/44/50 GHz Datasheet. Available online: https://www. keysight.com/it/en/assets/7018-03314/data-sheets/5990-9783.pdf (accessed on 10 July 2021).

42. Pozar, D.M. Microwave Engineering, 3rd ed.; Wiley: Hoboken, NJ, USA, 2004.

43. Nella, A.; Gandhi, A. Lumped Equivalent Models of Narrowband Antennas and Isolation Enhancement in a Three Antennas System. Radioengineering 2018, 27, 646-653.

44. Dashti, H.; Neshati, M.H. Input Impedance of Rectangular Substrate Integrated Waveguide (SIW) Cavity Backed Slot Antennas. In Proceedings of the 27th Iranian Conference on Electrical Engineering (ICEE), Tehran, Iran, 2-4 May 2017.

45. Balanis, C.A. Antenna Theory Analysis and Design, 4th ed.; Wiley: Hoboken, NJ, USA, 2016. 